\title{
BICHOS: INVESTIGANDO OS CONTORNOS DE UMA POÉTICA
}

Júlio Bernardo Machinski

Mestre em Literatura - UFSC
RESUMO: O presente ensaio é uma proposta de leitura do livro de poesia Bichos, de Renato Suttana. Neste exercício de análise, buscou-se superar a interpretação individual e privilegiar determinados aspectos da sensibilidade poética materializada nos poemas e seus significados possíveis.

PALAVRAS-CHAVE: Renato Suttana; Poesia Brasileira; Lirismo.

\section{BICHOS: INVESTIGATING THE}

LINEAMENTS OF A POETIC

ABSTRACT: This essay is a proposed reading from the book of poetry Bichos, of Renato Suttana. In this exercise of analysis, sought to overcome the individual interpretation and promoting certain aspects of the poetic sensibility embodied in poems and their possible meanings.

KEY-WORDS: Renato Suttana; Brazilian Poetry; Lirism. 
A um poeta não interessa aclarar o seu mistério nem que outros o aclarem num plano didático. Interessam o mistério mesmo e a posse das substâncias mágicas povoadoras do mistério.

Mauro Mota

As questões suscitadas pela advertência que Mauro Mota nos faz acima certamente já tomaram de assalto muitos daqueles que, em algum momento, dispuseram-se ao exercício crítico acerca da matéria poética. Aliás, o questionamento sobre a validade ou a necessidade de "apêndices didáticos" a respeito da arte estende-se para todas as suas formas de manifestação, não só a poesia.

À parte o grau de veracidade carregado pela opinião daquele poeta, não podemos desconsiderar o fato de que a leitura e o comentário crítico constituem-se em elementos importantes enquanto ativadores de determinado texto. Poucos são os autores que escrevem (e publicam) no intuito de que seus trabalhos permaneçam mergulhados no silêncio e no esquecimento. Além do mais, se realmente existem os poetas que prefiram a leitura de deleite, aquela que preservaria o tal mistério ao final do livro - se isso for possível - e que escolhem o mutismo a respeito das motivações e processos de seus fazeres poéticos, há outros que assumem posição diferente. Basta, por exemplo, lembrarmos de nomes como T. S. Eliot e Ezra Pound, referências obrigatórias no estudo da poesia moderna, para verificarmos que muitos poetas não só autorizam o exercício crítico sobre suas obras, como eles mesmos foram os principais críticos de suas poesias.

Afora essas considerações preliminares, parece-nos pertinente que, na leitura crítica de uma obra poética e em nome do rigor teórico, não sufoquemos o objeto motivador de nossas reflexões: a própria poesia. Foi o que procuramos fazer nas páginas que seguem, onde, sempre que possível, os poemas são chamados para dialogar com nossas considerações pessoais, muitas vezes, em tom mais claro e alto.

\section{I.}

Desde La Fontaine - sem ignorar, claro, a longa tradição oral anterior -, o animal tem sido, nas narrativas fabulares, retratado como espelho de comportamentos humanos ora louváveis, ora desprezíveis. Quem não lembra a história da cigarra e da formiga? Isolando a intenção de apontarmos as possíveis fontes textuais, podemos circunscrever um conjunto de sentenças que traduzem visões estereotipadas dos animais difundidas 
através dos tempos em muitas culturas. Nessa perspectiva, o lobo é mau; a raposa é traiçoeira; a cigarra é preguiçosa; a galinha é medrosa; o corvo é agourento; o urubu é desprezível; o tubarão é assassino; o macaco é risível, e por aí segue.

Numa classificação do conto popular brasileiro, Luís da Câmara Cascudo, em Literatura oral no Brasil, fixa a categoria 'Contos de Animais' (do inglês, animal tales) que seria, segundo palavras do autor, "a fábula legítima, no plano clássico e pedagógico que o povo manteve através de séculos", e ressalta:

Todas as estórias [sic] de animais têm a finalidade educacional. Não fixando matéria de ética, expõe uma espécie de documentário da sabedoria arteira, da habilidade invencível com que os entes humildes e fracos devem, aos olhos primitivos, defender-se dos fortes, arrogantes e dominadores ${ }^{1}$.

Conforme sugere o pesquisador, nenhuma história de animal poderia prescindir do critério ético, repressor e moral.

Entretanto, nem toda a literatura reserva aos animais o papel de inimigos naturais ou meros coadjuvantes na execução de projetos humanos. Dirigindo nosso olhar à literatura moderna, flagramos momentos em que o animal já não figura apenas para fins de comparação ou contraste aos comportamentos dos homens. Mesmo aqueles espécimes vistos como repulsivos e que, no cotidiano, por questão de higiene e saúde, devem ser eliminados de nosso convívio, são incorporados à criação literária, agora dotados de novas significações. Caso paradigmático vem-nos de Kafka que, em $A$ Metamorfose, propõe a transformação em inseto do protagonista Gregor Samsa. É o ser abjeto, objeto de fobias e símbolo de imundície anunciando-se, poderíamos mesmo afirmar, como parte de um processo de higienização existencial. O poder da imagem kafkiana proposta por essa obra foi tal que, décadas mais tarde, Clarice Lispector, uma das maiores representantes da literatura nacional de feição intimista, recupera o motivo em A paixão segundo G.H., dotando-o de um cunho ontológico ainda maior e criando uma cena em que, talvez, jamais o convívio entre o homem e um ser de outra espécie foi representado com tamanha profundidade. A própria Clarice, em "A explicação inútill", trata de sua percepção sobre os bichos:

...parece-me que sinto os bichos como uma das coisas ainda muito próximas de Deus, material que não inventou a si mesmo, coisa ainda

${ }^{1}$ CASCUDO, L. C. Literatura oral no Brasil. 2. ed. Rio de Janeiro: José Olympio, 1978. p. 294. 
quente do próprio nascimento; e, no entanto, coisa já se pondo imediatamente de pé, e já vivendo toda, e em cada minuto vivendo de uma vez, nunca aos poucos apenas, nunca se poupando, nunca se gastando ${ }^{2}$.

$\mathrm{O}$ ambiente harmônico ou de mera disputa entre homens e animais cede espaço agora para uma relação mais problemática, em que o animal, mais que o outro, é a chave para o despertar de uma consciência existencial mais aguda e, portanto, mais angustiante. Disso não resulta, vale ressaltar, a comprovação da hipotética superioridade do homem, mas, pelo contrário, encaminha ainda mais para a idéia do "homem, animal entre os animais" ${ }^{3}$.

II.

É assim, dignificados a partir de suas singularidades, que comparecem os animais retratados em cada poema da coletânea Bichos, de Renato Suttana ${ }^{4}$, essa pequena obra-de-arte surgida em 2005. Os termos anteriores assim se definem: pequena pelo formato adotado; obra-de-arte pelo cuidado primoroso que a edição apresenta.

A materialidade do livro funciona muito bem enquanto suporte metonímico do conteúdo que encerra. A começar pela capa, feita de papel-cartão pardo, à maneira de reciclado, cujas fibras que se desprendem e se tornam visíveis das dobras e nas bordas traem a origem orgânica do artefato e sugere uma breve genealogia das formas, fazendo lembrar que o papel, um dia madeira, foi extraído da árvore, que junto a muitas outras compôs o ambiente selvagem, habitat primitivo e natural dos animais. O que se tenta a seguir é uma leitura dessa obra que esteja orientada por aquilo que Alfredo Bosi

\footnotetext{
${ }^{2}$ LISPECTOR, C. Para não esquecer. Rio de Janeiro: Rocco, 1999. p. 71.

${ }^{3}$ Ainda na obra de Clarice é possível encontrar outros momentos em que o animal é representado com o status de importante elemento no projeto de investigação existencial do si mesmo. Além do tratamento simbólico dedicado à figura dos cavalos, emblemático tornou-se o conto "Uma galinha", que narra a relação afetiva da protagonista com essa criatura, vista comumente como componente ou provedora de víveres, mas que, na narrativa em questão, é eleita animal de estimação, destinatária de afetos e cuidados. Outro escritor brasileiro, o catarinense Cristovão Tezza, retoma o motivo e, em parte, a mesma situação (a morte do animal e os angustiantes momentos que antecedem o evento) e dá-nos uma versão, digamos assim, masculina da narrativa num fragmento do romance Trapo que foi adaptado para a forma de conto com o título "A lembrança mais antiga de minha vida". Aqui, quem aparece não é a galinha, mas o galo, "Um galo branco, de crista sanguinolenta e meio caída, como quem vem da guerra". In: TEZZA, C. "A lembrança mais antiga de minha vida".

Disponível em: <http://www.cristovaotezza.com.br/textos/contos/p_lembranca.htm>.

${ }^{4}$ Informações biográficas e literárias a respeito do autor podem ser acessadas através do sítio pessoal mantido na internet, no endereço: <http://www.arquivors.com>.
} 
classificou como "um modo de perceber as imagens do poema capaz de abraçar generosamente corpo e historicidade, matéria e significação"

Cada um dos vinte e três poemas que compõem a obra homenageia um animal diferente (vinte e um no total, pois dois poemas são dedicados à galinha e à carriça). Entre o título e o corpo verbal de cada poema o texto é iluminado por uma ilustração de tipo xilográfico, espécie de epígrafe imagética, do escritor e artista plástico português Nicolau Saião, que também assina a apresentação do livro. São imagens simples, traços espontâneos numa moldura retangular que em alguns momentos - no caso da cigarra, por exemplo - sugerem o desenho infantil, a compor poemas visuais que estão a dialogar discretamente com a simplicidade formal também adotada na estrutura poética frasal.

São poemas de extensão curta, muitos compostos de três ou quatro estrofes apenas, alguns, como estes, a quase se realizar em haicai, já trazendo e traduzindo formalmente lições de serenidade e simplicidade dadas pela natureza:

No mundo da ferocidade o gato carrega, sereno, a sua verdade.

Mais que um pecado, a serpente nos ensina a simplicidade ${ }^{6}$

A idéia da natureza como repositório de mistérios e conhecimentos a serem buscados pelo homem perpassa toda a obra. Nesse universo de exploração, a tentativa do poeta de delinear a forma e o comportamento de cada animal deve servir de aproximação a alguma espécie de entendimento, e os bichos aí estão como vias para a apreensão de significados esclarecedores do mistério da natureza.

A ânsia que marca a luta pela sobrevivência pode se traduzir em violência, como em "O leopardo", poema que abre o livro:

O leopardo -

ele tem de lutar

\footnotetext{
${ }^{5}$ BOSI, A. "Sobre alguns modos de ler poesia: memórias e reflexões". In: São Paulo: Ática, 2001.p. 42. (org.) Leitura de poesia.

${ }^{6}$ SUTTANA, R. Bichos. Guarapuava: ed. do autor, 2005. [todos os poemas e fragmentos citados pertencem a esta edição].
} 


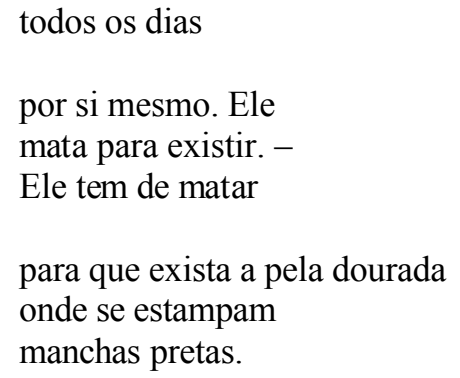

Outras vezes, tal luta para o existir se dá por estratagemas de disfarce e adaptação, como em "O polvo":

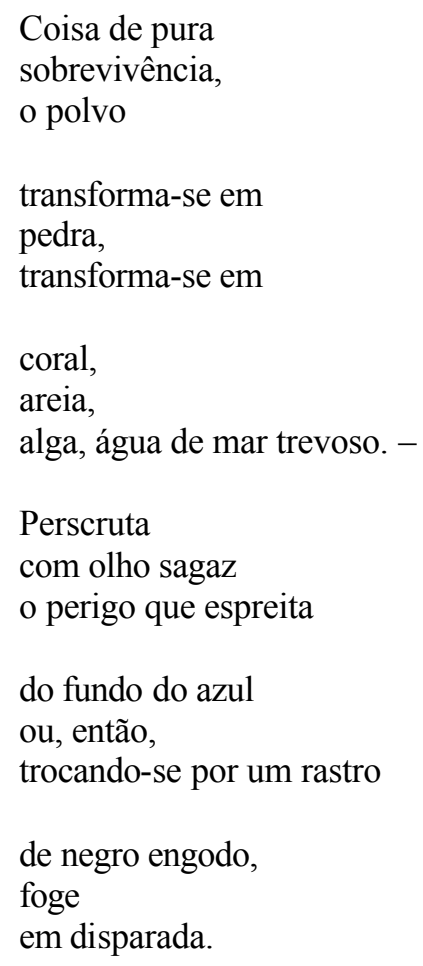

Há em poesia, como sabido, a premissa da síntese, de que a imagem poética construída verbalmente seja detentora de força sugestiva suficiente para dar conta do real representado, às vezes até mesmo superando-o pelo poder da metáfora. Tal premissa se faz cumprir em momentos distintos da obra como, ao tentar definir os contornos da abelha, apontando a antítese constitutiva desse ser, o poeta pergunta:

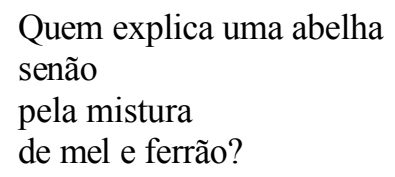


Já em "A águia”, animal que o poeta confessa só conhecer dos livros, mas sabe serem "fragmentos alados de morte e beleza", a síntese ressalta no terceto final ao trazer a afirmação de que essa ave

Vive de ser a medida que vai da ponta da asa à ponta da garra.

Se, como traz o poema, a águia "captura o exato / com seu olho de águia", vale intuir que o poeta tenta captar e oferecer a essência da águia com seu olhar de artista sobre o mundo circundante, e ultrapassa o desenho das formas delimitadas que a razão vai buscar na natureza.

Cada poema é um todo fechado, uma peça de linguagem onde os elementos imagens, ressonâncias, silêncios, motivos - se relacionam de forma a constituir um conjunto homogêneo. Se pensarmos na musicalidade da poesia, podemos tomar o poema como uma partitura, cuja integridade formal depende da justaposição das notas e da combinação hábil de seqüências rítmicas e hiatos. A circularidade é um dos aspectos que contribuem para que o poema se realize em um artefato orgânico. É, justamente, a circularidade que ressalta na leitura de "O leão":

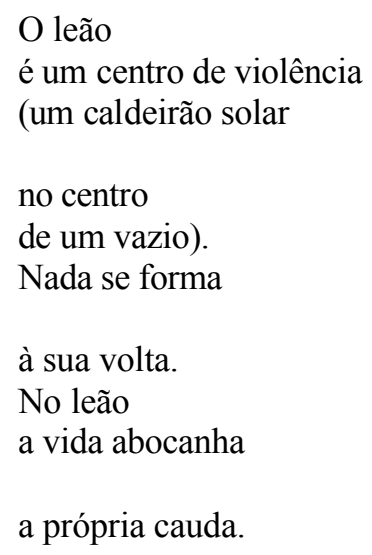

Não podemos afirmar com segurança que a circularidade é atingida por um processo consciente do poeta, mas é possível apontar no texto alguns dos elementos que a tornam visível. O leão é definido como "centro de violência": o conceito de centro, em geral, transforma-se mentalmente para nós na imagem de um ponto, algo em torno do que outros elementos se agregam ou se dispersam. No poema, a imagem é reforçada pela repetição do termo: centro de violência / no centro de um vazio. O que está no 
centro do vazio é "um caldeirão solar" - outras duas imagens, caldeirão e sol, que têm objetivamente forma circular. É num espaço circunferencial também que nada se forma: à sua volta. Para fechar a circularidade do poema, a idéia de que "no leão / a vida abocanha / a própria cauda", sugerindo a imagem do animal girando em círculos, na ameaça iminente de unir as extremidades de seu corpo e realizar, objetivamente, o centro que o poeta visualizou.

Algumas ilustrações, por sua multiplicidade de linhas e curvas, uma saturação de formas respingantes, como a ilustração do poema "O lagarto", por exemplo, feita de pontilhados em negativo, fazem lembrar as gravuras que enfeitam as edições artesanais dos folhetos do cordel nordestino.

Também como enfeites, emolduradas e penduradas na parede de um cômodo familiar, poderiam ser vistas as ilustrações do tubarão e da pulga, com seu algo de mosaico e algo da arte portuguesa da pintura de azulejos, rasgos, talvez, a trair a nacionalidade do artista que as produziu.

Se a proposição anterior parece descabida, vale observarmos que a experiência de leitura da literatura anula, muitas vezes, os limites entre o espaço da obra e o espaço do mundo ou, ao menos, torna relativos ou mescla esses limites. Benedito Nunes aponta "a afinidade entre o espaço próprio da obra, por ela mesmo formado, e a autonomia do espaço"7, sugerindo essa afinidade como um dos traços característicos das artes plásticas após a ruptura que o cubismo operou na perspectiva espacial geométrica como meio de representação do real.

As ilustrações e os poemas ainda dialogam por outras vias: a técnica do negativo, do branco e preto que desenham as formas, reaparece em jogos de claro-escuro que o poeta constrói por impressões como estas: o besouro é uma semente preta que estrajela contra a janela; o lagarto é uma mancha negra no muro; o tubarão é um monstro limpo no escuro. Entretanto, os exemplos que melhor ilustram o contraste dos desenhos pela antítese das cores são estes:

$$
\begin{aligned}
& \text { De repente } \\
& \text { na parede branca } \\
& \text { a barata preta. } \\
& \text {.... } \\
& \text { Uma pulga } \\
& \text { é um ponto negro }
\end{aligned}
$$

\footnotetext{
${ }^{7}$ NUNES, B. Crivo de papel. São Paulo: Ática; Rio de Janeiro: Fundação Biblioteca Nacional; Mogi das Cruzes: Universidade Mogi das Cruzes, 1998. p. 80.
} 
de desassossego

na calma

branca

dos lençóis.

É dessa maneira, por uma economia de cores e de forma delicada que os animais são destacados da paisagem: ao invés de uma descrição excessiva, o poeta prefere esboçar os contornos das formas que tateia.

A percepção das formas dos animais que o poeta delineia não acontece sempre por um contato direto com a natureza, que seria o caso se se tratasse de um profissional das ciências naturais, um zoólogo ou outro pesquisador da fauna. Há elementos intermediadores na observação de algumas espécies que ele toma como tema. Durante a leitura do livro é possível perceber cartas nuances no grau de intimidade ou familiaridade entre o poeta, enquanto observador comum, e um bicho ou outro. Claro, é bem mais provável que já tenhamos tido a experiência de observar uma galinha em seus passeios pelo terreiro doméstico, ou dentro dos limites de um galinheiro; passamos cotidianamente por encontros furtivos, acidentais ou propositais, com uma abelha, um gato, uma barata; mas não é usual, coisa corriqueira, que tenhamos a chance de observar pessoalmente um leopardo, um leão, um elefante ou mesmo um porco-espinho. Há sinceridade do poeta ao tornar explícitos os suportes mediadores: a águia ele só as vê em livros; o tubarão é visto no televisor.

A rima não parece constituir o cerne das preocupações do poeta. Embora os poemas possuam inegável ritmo e sonoridade, esses resultam preponderantemente do manejo hábil de outros recursos: pausas, aliterações, alternância de versos curtos e longos, parênteses (que mais ressaltam que apartam, reforçando as imagens), cortes no final dos versos que propiciam um enjambement fluente. Um dos poucos casos de poema rimado é "O porquinho-da-índia", animal, aliás, que também já foi objeto do lirismo afetivo de Manuel Bandeira em conhecidos versos. Se, em Bandeira, o animalzinho era o mimo do poeta quando criança, mas que insistia um fugir aos carinhos e preocupações que este lhe dedicava metendo-se debaixo do fogão, em Suttana o porquinho-da-índia é colocado numa situação-limite - encara seu trágico destino abandonado no lar do inimigo: 


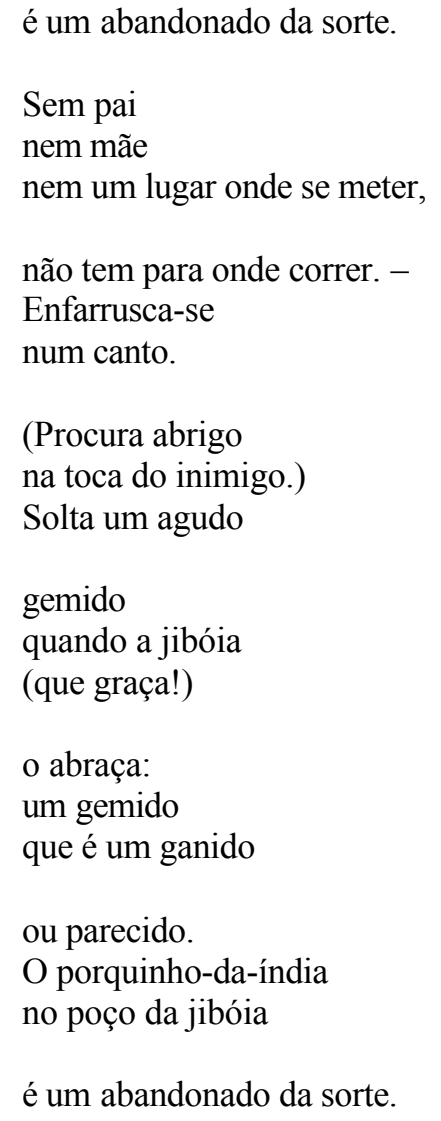

Ainda aqui, percebemos que a rima é acidental: se insinua na metade do texto, ganha força na ironia do abraço fatal, mas desaparece antes que termine o poema. Novamente, a circularidade se efetiva pela retomada da estrofe inicial que encerra o poema e reforça o caráter trágico da situação.

No poema "O gato", o sentido do texto é enriquecido pela sonoridade que perpassa os versos:

No mundo da ferocidade o gato carrega, sereno, a sua verdade.

Sobre o muro, onde pausa para olhar os arredores, observa o casal de rolas

e seus amores.

Gatos não pensam (?), mas o olho que volve para trás,

para olhar os arruladores, faz pensar que pense que um casal de rolas 


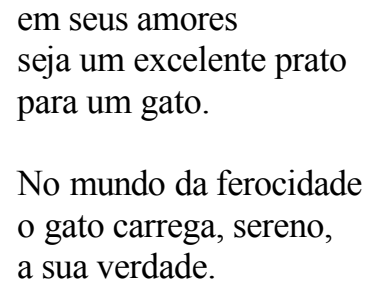

A recorrência do fonema / $\mathrm{r} /$ recria vocalmente o ronronar do gato: "ferocidade", "sereno", "sobre", "muro", "para" são exemplos de morfemas com o 'r' alveolar extraídos das duas estrofes iniciais. $\mathrm{Na}$ seqüência "carrega"-"arredores"-"rolas""arruladores", o emprego do 'r' uvular parece imitar o som típico que emitem os gatos quando se sentem ameaçados.

A mesma imagem-acústica reaparece na estrofe final do poema "A serpente", onde o 'r' de "arrasta", "relva", “enrosca”, sugere algo do ruído que a serpente produz quando rasteja, algo também do cicio que marca o bote: Por isso se arrasta na relva,
por isso se enrosca num tronco -
e devora em silêncio.

O mesmo som, somado à repetição da estrutura que forma os dois primeiros versos, iniciados ambos pela conjunção conclusiva "por isso", insinua o movimento ondulante que a serpente realiza ao deslocar-se e enrolar-se no tronco.

No poema "O besouro", o poeta realiza uma junção entre a imagem-visual e a imagem-acústica, misturando som e cor, ao oferecer a imagem-síntese desse "serbesouro", cuja perfeita adequação de corpo, propõe o poeta, teria passado despercebida a Kafka, numa alusão clara ao tema de $A$ metamorfose:

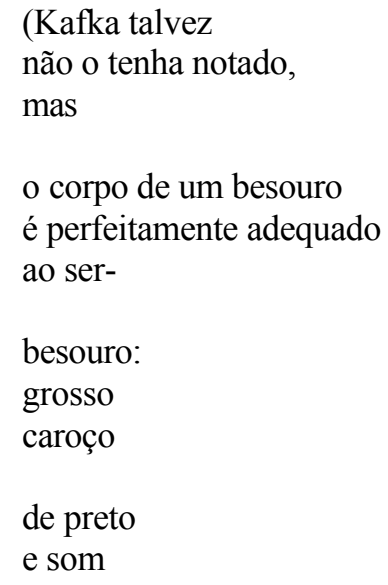


lançado ao vento.)

Já a imagem-síntese de "A cigarra", propõe a redução desse inseto no som estridente que produz e que costuma marcar os dias ensolarados de verão. A própria extensão do texto reforça a idéia de contingência. Eis o poema todo:

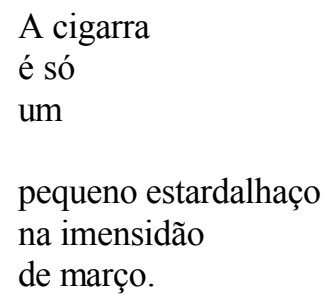

As imagens que o poeta vai criando ao longo do livro acabam por contrapor a quietude de cada animal (lembremos que eles são tomados individualmente e nunca em bando) e o comportamento humano muitas vezes ruidoso. Entretanto, ressalvamos, tal observação resulta de uma operação de leitura, pois em nenhum momento o autor faz uma comparação direta entre o homem e o animal. Ao leitor, por sua vez, não passam despercebidos a serenidade do gato, a simplicidade e o silêncio da serpente quando devora, o aspecto de estátua do rinoceronte parado, a resignação melancólica do elefante, a pequenez da carriça, a humildade do porco, o vagar da tartaruga. Tais traços sugerem que o poeta decidiu flagrar os animais colecionados num momento de intervalo ou breve pausa dos deslocamentos incessantes aos quais a luta pela sobrevivência obriga, ao mesmo tempo em que nos força a um questionamento acerca de nossa maneira de estar no mundo, nossa pressa, nossa necessidade de evidência, nossa inquietude advinda justamente daquilo que nos distancia dos outros animais e nos afasta, muitas vezes, de nossa própria natureza.

Cabe dizer, no entanto, que o poeta não foi buscar o modelo da fábula ao traçar sua poética sobre os bichos, isto é, não constitui premissa da obra resgatar comportamentos exemplares, extrair lições morais da vida animal, nem fazer um mapeamento das espécies com cunho pedagógico. Não estão aqui destacados, a erigir modelos de conduta, o existir laborioso das formigas operárias, a dedicação do joão-debarro ao construir seus ninhos, o papel da gralha-azul na perpetuação da araucária, nem a fidelidade conjugal das araras ou a fidelidade canina ao seu dono. Talvez, a ausência mesma desses animais - já que, curiosamente, nenhum apareceu no livro - tenha algo a nos dizer a esse respeito. Sobre a abelha, por exemplo, ao invés de destacar o seu papel 
na reprodução das flores, a construção e o funcionamento organizado das colméias, a fabricação do mel, tido como o mais puro dos alimentos, o poeta prefere simplesmente alertar que:

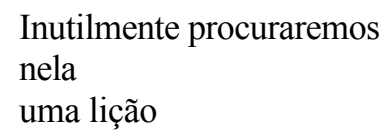

Se há algum ensinamento se insinuando entre os textos, é de forma indireta e sutil que as lições nos alcançam, ou que as alcançamos nós, se estivermos dispostos a buscá-las entre os flagrantes fixados pelo olhar sensível que o poeta lança ao mundo dos bichos.

O poeta não se coloca acima dos animais, não decreta o estatuto de inferioridade dos bichos, e até torna relativa essa visão como quando põe em suspensão o pressuposto: "Gatos não pensam(?)"; ou quando sublinha a forma errática e um tanto patética de nossa percepção desses seres outros:

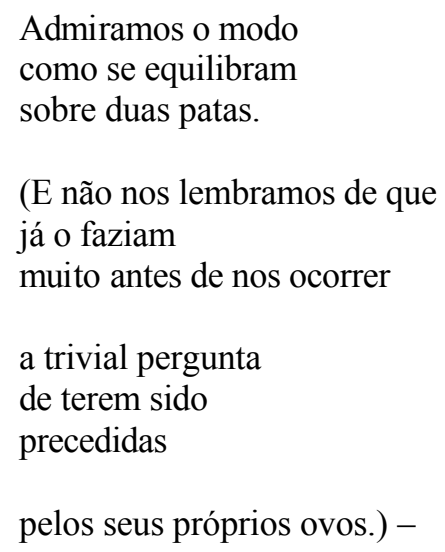

Mesmo os macacos, pintados como palhaços, são, ainda assim, "palhaços inapreensíveis" a nos dizer que o mundo é selvagem. E o poeta segue nos dizendo que "se um macaco olhar para um espelho, verá apenas um macaco", ao passo que nós, se olharmos para o espelho, o que vemos? O que somos capazes de ver além de nós mesmos? Talvez seja justamente pela consciência de nossa visão fatalmente distorcida que o poeta apresente certo cuidado e humildade ao tratar de cada animal. Não tendo a pretensão de traçar o desenho definitivo, opta por alcançar o mundo selvagem por suas bordas, muitas vezes, alcançando o âmago. Talvez, porque, ao tentarmos construir qualquer imagem do mundo ou de nós mesmos seja a humildade a única condição que nos é de antemão exigida. 
III.

No livro de poemas anterior de Suttana tentamos perseguir as imagens da insônia e da solidão. Em "Bichos", a insônia se insinua (num parênteses) no poema "A pulga" que, diz o poeta: "Imiscui-se (na noite insone)". Embora em nenhum momento o poeta aborde a solidão - a própria palavra está ausente ao longo de todo o livro - o fato de, como já aludimos anteriormente, os animais serem tomados individualmente resulta na impressão de estarem todos mergulhados numa espécie de solidão cósmica. Não há intercâmbio entre o lócus específico de cada um, os bichos não estão como elementos constituintes de um espaço de trocas. A esboçar o desenho dessa solidão, parecem estar as imagens do espelho, do ar inabordável, da televisão, do escuro, do fundo azul das águas do mar trevoso, da "tarde do não" onde o elefante passeia sua resignação e melancolia, do deserto alado, da parede branca.

Toda lição que se quiser buscar, toda observação que se quiser fazer, todo contorno que se quiser definir em relação ao bicho, enquanto outro ao homem - "porque é ao entendermos o Outro (e que outro mais outro pode haver que um animal, um bicho?) que melhor nos vemos", afirma Nicolau Saião no texto de apresentação do livro - o poeta só poderá fazê-lo a partir de suas possibilidades, do que lhe é familiar, do que é caracteristicamente humano. Por isso, podemos nos ver "uma forma intratável e aparência inabordável" tal como o porco-espinho; por isso, para sobreviver, podemos assumir diversas formas tal como o polvo; por isso, às vezes, nos sentimos abandonados da sorte, sem pai, sem mãe nem um lugar para correr, como o porquinho-da-índia no poço da jibóia; por isso, como o leopardo, temos de lutar todos os dias por nós mesmos; ou então, simplesmente, como o lagarto, às vezes, abandonamos nossas pretensões e permitimo-nos ficar congelados no instante, digerindo nossa própria eternidade.

\section{REFERÊNCIAS}

BOSI, A. "Sobre alguns modos de ler poesia: memórias e reflexões". In: (org.)

Leitura de poesia. São Paulo: Ática, 2001.

CASCUDO, L. C. Literatura oral no Brasil. 2. ed. Rio de Janeiro: José Olympio, 1978. LISPECTOR, C. Para não esquecer. Rio de Janeiro: Rocco, 1999.

NUNES, B. Crivo de papel. São Paulo: Ática; Rio de Janeiro: Fundação Biblioteca Nacional; Mogi das Cruzes: Universidade Mogi das Cruzes, 1998. 
SUTTANA, R. Bichos. Guarapuava: ed. do autor, 2005. 